\title{
Preliminary results on the effects of orthopedic implant stiffness fixed to the cut end of the femur on the stress at the stump- prosthetic interface
}

\author{
I.Boudjemaa, A. Sahli, A. Benkhettou, S.Benbarek \\ Department of Mechanical Engineering, Laboratory Mechanics Physics of Materials (LMPM), University of SidiBel Abbes, BP \\ 89, cite Ben M'bidi, SidiBel Abbes, 22000, Algeria \\ ismailboubou000@gmail.com \\ sabliabderabmen@yahoo.fr,bttp:/ / orcid.org/0000-0002-5183-1168 \\ aekben.dr22@gmail.com \\ sma_benbarek@yahoo.fr, bttp://orcid.org/0000-0002-5420-9144
}

\begin{abstract}
People with trans-femoral amputation often experience skin breakdown due to the pressures and shear stresses in the stump-prosthesis interface. In this study, a finite element model was employed to investigate the stresses at the stump interface in the case of an orthopedic implant fixed to the cut end of the femur. By changing the stiffness of this implant, we aim to see how the stiffness of this implant affects the stresses in the interface between the amputated limb and the prosthesis. To find out the effects of implant stiffness, five values for the elastic modulus, ranging from 0.1 to 0.5 $\mathrm{MPa}$, with an interval of $0.1 \mathrm{MPa}$ were employed in the implant structure of the FE model.

Obtained results show that the implant played important role in reducing the stresses at the stump-prosthesis interface where the contact pressure did not exceed $53 \mathrm{kPa}$ and $17.3 \mathrm{kPa}$ for shear stress in the stiffer case of an implant, while the contact pressure in the case of femur without an implant exceeded $79 \mathrm{kPa}$ and $42 \mathrm{kPa}$ for shear stress. We also noted that the intensity of the contact pressure and the shear stress is proportional to the stiffness of the implant, as the greater the implant stiffness, the higher the peak of these stresses.
\end{abstract}

KEYwORDS. Prosthesis; Stump interface; Stiffness; Contacts stresses; Implant.

\section{OPEN $\odot$ ACCESS}

Citation: Boudjemaa, I., Sahli, A. Benkhettou, A., Benbarek, S., Preliminary results on the effects of orthopedic implant stiffness fixed to the cut end of the femur on the stress at the stump-prosthetic interface, Frattura ed Integrità Strutturale, 57 (2021) 160-168.

Received: 16.04 .2021

Accepted: 06.06.2021 Published: 07.01.2021

Copyright: (C) 2021 This is an open access article under the terms of the CC-BY 4.0, which permits unrestricted use, distribution, and reproduction in any medium, provided the original author and source are credited.

\section{INTRODUCTION}

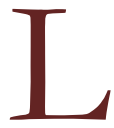

ower limb amputations are mainly due to traffic accidents, particularly motorcycle accidents [1], diabetes and cancer are also major causes of amputation [2,3]. After lower limb amputation the patients need a prosthesis to retain upright mobility capabilities, unfortunately, many of them remain dissatisfied with the performance of this 
prosthesis [4], some patients also suffer from deep problems with this prosthesis, like discomfort, redness, sores, and inability to stand for a long time [5]. The stresses at the stump-prosthetic interface are primarily responsible for these problems.

Several studies have discussed the stresses at the residual limb interface using the finite element method (FFM) [6-18]. The models developed in these studies can be divided into three types. The first type involves linear static analysis established under assumptions of linear material properties, the second type can be referred to as nonlinear analysis, taking into consideration the nonlinear material properties, and the third type involves dynamic models. Analyses of this type consider not only dynamic loads but also material inertial effects and time-dependent material properties [19, 20]. Jia et al (2004) [18] performed a (FE) study on the influence of inertial load on interface pressure and shear stress, the socket was modeled as rigid in the study, and all materials were assumed linear. Lacroix et al (2011) [14], developed five EF models from five different patients to study the effect of the socket donning process on the stress-strain state at the outer residual limb interface. The main goal of the study performed by Zhang et al (2013) [13] was to predict the stress distribution between the socket and the residual limb, in this study a prosthetic liner with $5 \mathrm{~mm}$ thickness has been used. Meng et al (2020) [7] investigated the residual limb stress of trans-femoral amputees Compression/release stabilized (CRS) socket by finite elemental modeling. Most of these studies applied a load equivalent to half or full body weight at the bone head or they apply forces equivalent to the reaction forces extracted from larger (FE) models.

Medical implants are devices that can place inside or on the surface of the body, these implants can replace body parts and function or provide support to organs and tissues. A soft implant under the cut end of the femur bone (fig. 1) could be one of the suggested solutions, as it helps the bone to increase the ability to carry weight and thus reduce stresses on the stump-prosthetic interface also help to cushion the end of the femur bone. 2D simulation of this type of orthopedic implant has previously been performed in Chillale's study [11].

In this study, an implant that is fixed to the cut end of the amputated femur bone (fig. 2) was simulated, we aim by employing a 3D finite element model to investigate the effect of this orthopedic implant stiffness on the stresses at the stump-prosthetic interface. To find out the effects of implant stiffness, five values for the elastic modulus, ranging from 0.1 to $0.5 \mathrm{MPa}$, with an interval of $0.1 \mathrm{MPa}$ were employed in the implant structure of the FE model.

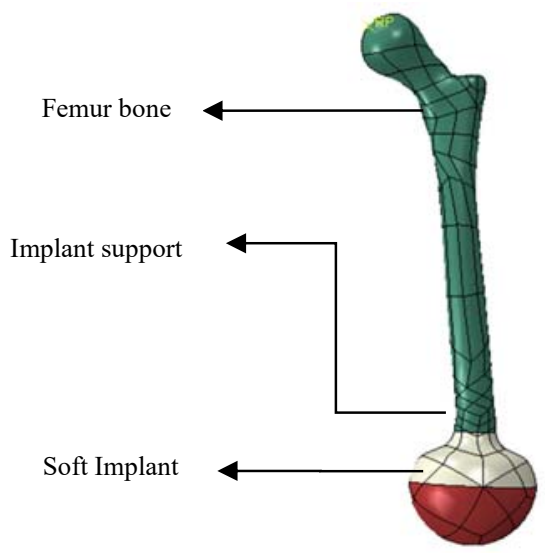

(a)

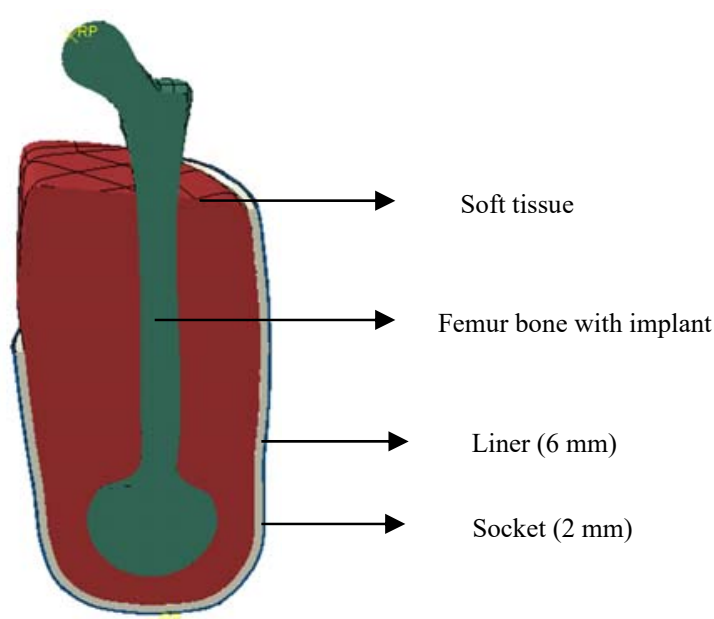

(b)

Figure 1: Schematic representation of the (EF) model, (a) bone with implant parts, (b) the different sections of the 3D (EF) model geometry (bone, soft tissues, implant, liner, and socket).

\section{METHOD}

Geometry finite element (FE) model for a virtual patient was developed to simulate an above-the-knee amputation, this model is composed of a limb (soft tissue, bone, implant, and implant support) and a prosthesis with a prosthetic liner and socket. The liner and the socket were designed using Autodesk Meshmixer this software allows to adapt 
the prosthetic liner shape to the residual limp, the liner was considered to be $\mathbf{6} \mathrm{mm}$ thick, as for the socket, it was $\mathbf{2} \mathrm{mm}$. The model has been converted from STL to IGS with MIMICS 3- MATIC software. The different parts are shown in fig 1.

The implant was developed in the $(\mathrm{EF})$ model with two principal parts, the top was the support part for the soft implant with a height of $45.5 \mathrm{~mm}$, and the diameter of the soft implant was $45 \mathrm{~mm}$ [11] as shown in Fig. 2.

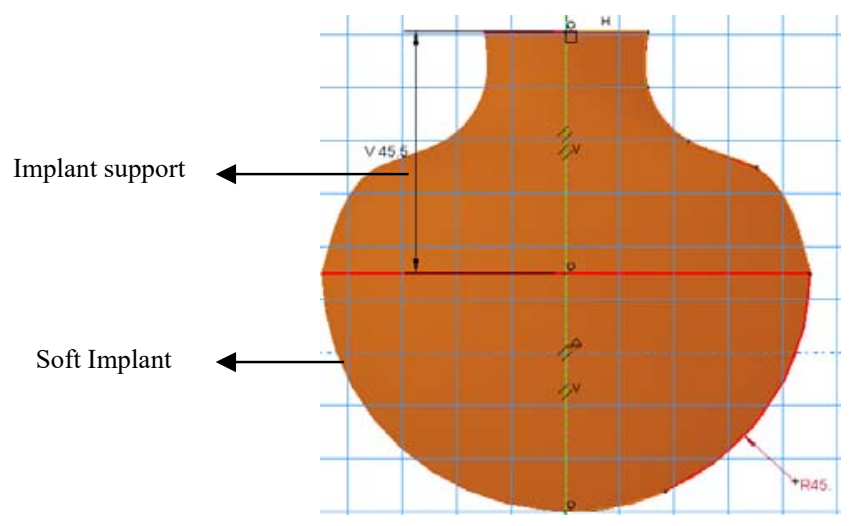

Figure 2: Schematic representation of implant geometry

\section{Mechanical properties}

The material properties of the femur bone, soft tissue, implant support, implant, liner, and socket were assumed to be linearly elastic, homogeneous, and isotropic. The list of the values of elastic modulus and Poisson's ratio used in the finite was shown in Tab. 1.

The Young's modulus of the implant was changed from 0.1 to 0.5 [17] to predict how the stiffness of the implant affected the stresses at the limb-prosthetic interface.

\begin{tabular}{ccc}
\hline Material & Young's modulus & Poisson's ratio \\
Bone [16] & $10 \mathrm{GPa}$ & 0.3 \\
Soft tissue [18] & $0.2 \mathrm{MPa}$ & 0.49 \\
Implant support [11] & $5.5 \mathrm{MPa}$ & 0.38 \\
Implant [17] & 0.1 to $0.5 \mathrm{MPa}$ & 0.49 \\
Liner [18] & $0.38 \mathrm{MPa}$ & 0.39 \\
Socket [16] & $1.5 \mathrm{GPa}$ & 0.3 \\
\hline
\end{tabular}

Table 1: details material properties for the (FE) model $[11,16,17,18]$

\section{Boundary and loading condition}

In this study, a non-linear finite element static analysis method was used. This analysis employed multiple finite element techniques, including geometric non-linearity due to large deflections, non-linear contacts due to friction between the contact surfaces of the stump and the prosthetic.

The interfaces between the femur bone with the implant and soft tissue were tied; the physical contact between the stump and the liner and between the liner and the socket was represented by using surface-to-surface contact condition, which impede the residual limb nodes (slave nodes) to trespass or penetrate into the socket (master surface) during the displacement caused by the application of body weight. The coefficient of friction between the liner and soft tissue was assumed to be $0.5[13,20]$. Although the bone is considered quasi-brittle material [21, 22], however, it is responsible for carrying human weight. In this study static vertical load equivalent to the half body weight [23] $350 \mathrm{~N}$ (two-leg stance) was applied on the femoral bone head, the distal end of the socket was fixed. 


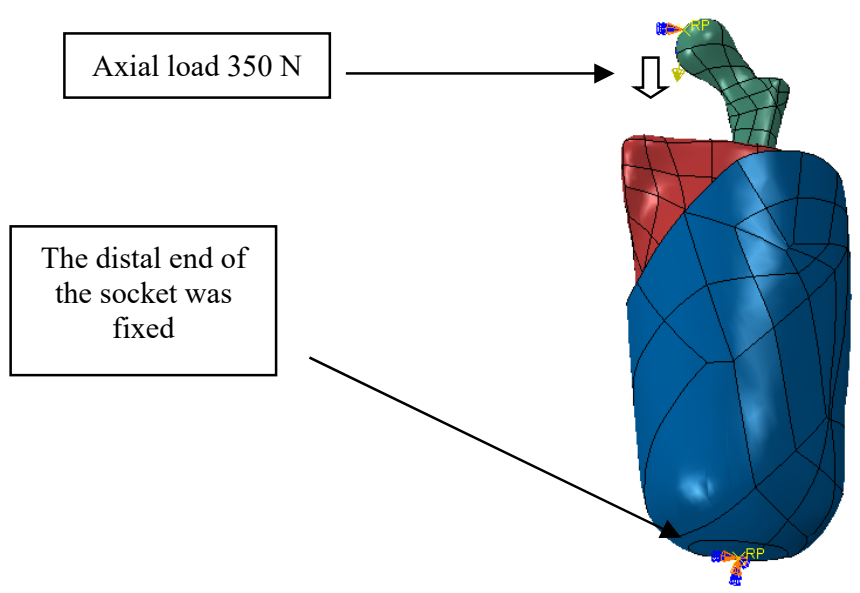

Figure 3: Schematic representation of load and boundary conditions

Mesh

The reliability of the results obtained requires a very refined mesh. The meshing was performed using C3D4 tetrahedral elements (C-continuum, 3D-three dimensional element, and 4- four noded element) for all components (bone, stump, liner, socket, and implant), tetrahedral meshes are generally preferred over hexahedral meshes for free-formed complex geometries as the former are computationally more cost-effective [24]. The total number of elements and element types for all components are specified in Tab. 2.

\begin{tabular}{ccc}
\hline Parts & Elements number & Element type \\
Soft tissue & 53214 & C3D4 \\
Liner & 17933 & C3D4 \\
Socket & 19413 & C3D4 \\
Bone with implant & 12749 & C3D4 \\
Bone without implant & 8984 & C3D4
\end{tabular}

Table 2: Mesh properties used
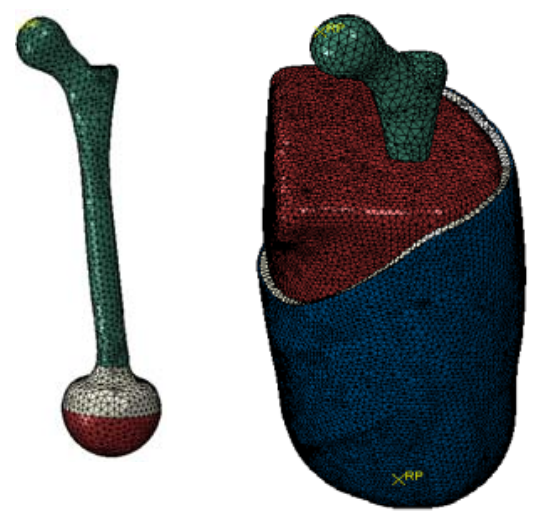

Figure 4: Mesh of the analyzed (FE) model 


\section{RESULTS}

$\mathrm{R}$

esults represent the predictions of residual limb reaction after patient weight application in all cases in this simulation.

Distribution of Von Misess stress in the femur bone and the soft tissue with implant 0.1 and without implant was shown in fig 5. The maximum Von Mises in the femur in the case with the implant was $65.9 \mathrm{kPa}$ almost double of Von Mises recorded in the case without an implant $(36.3 \mathrm{kPa})$, this proves that the soft implant increases the weight carrying ability of the amputated femur.

The maximum Von Mises stress in the soft tissue in the case with implant 0.1 was $11.5 \mathrm{kPa}$ this is less than that recorded in the case without implant that was $42 \mathrm{kPa}$. The stresses in the case of residual limb without implant recorded high concentration under the truncated femur bone region, this proves that the soft implant was played an important role in cushioning the end of the amputated bone and reducing the stresses on the soft tissue.

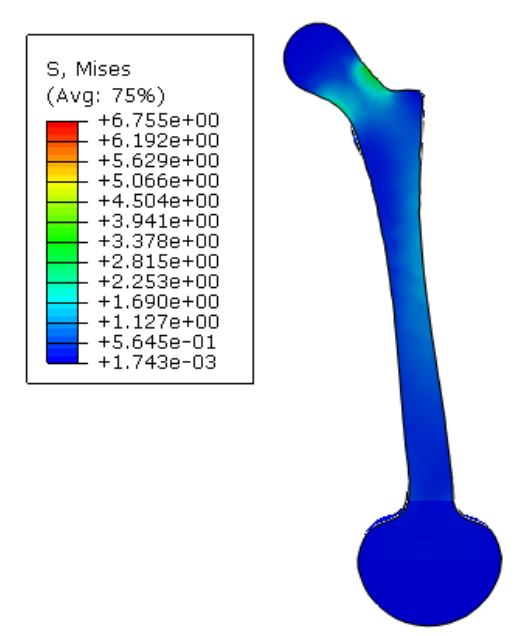

Bone with implant $0.1 \mathrm{MPa}$ (Young's modulus)
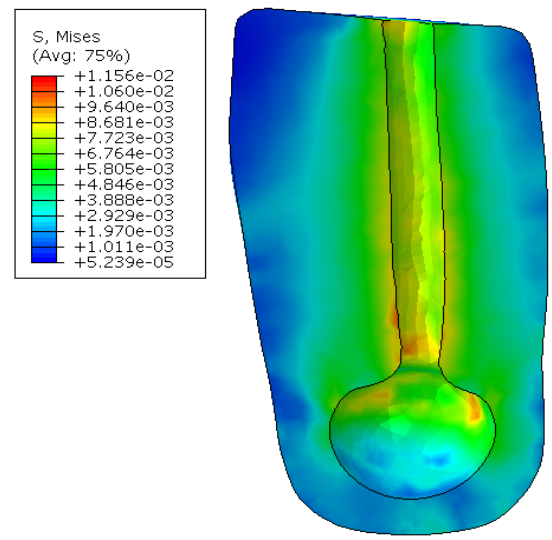

Soft tissue in the case of implant 0.1 $\mathrm{MPa}$ (Young's modulus)

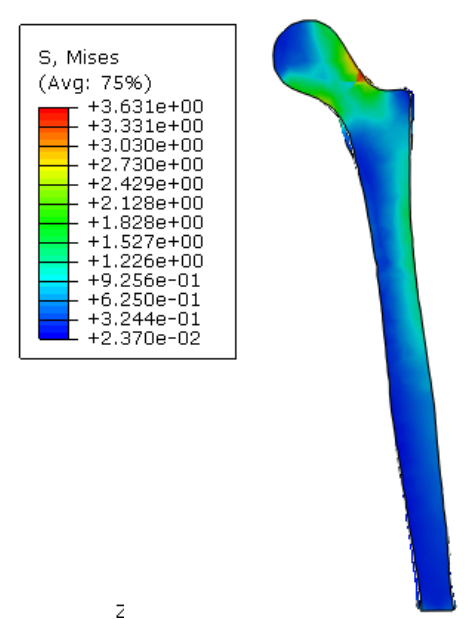

Bone without implant
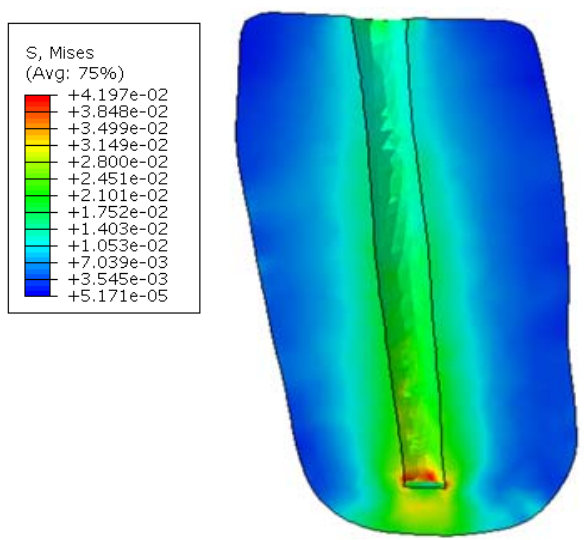

Soft tissue in the case without implant

Figure 5: Von Mises stress distribution (MPa) on the limb with and without implant 
Fig 6 shows the distribution of contact pressure at the stump-prosthetic interface in all cases of implant stiffness and the case without an implant.

In the case without an implant, we get a high concentration of contact pressure under the truncated femur region; the peak pressure, in this case, was $79.7 \mathrm{KPa}$.

In the case of the implant below the amputated bone, we noticed that the intensity of the contact pressure at the outer stump interface rises with the increase of stiffness of this implant. The highest peak contact pressure between the implant cases was $53 \mathrm{KPa}$ at the implant (0.5 MPa Young's modulus). The lowest peak contact pressure was recorded in the limb in the case of the least stiffness implant (0.1 MPa Young's modulus) up to $45 \mathrm{KPa}$.

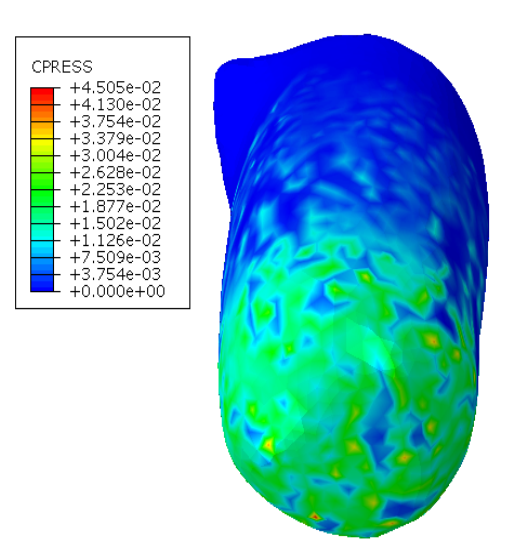

The Stump at implant $0.1 \mathrm{MPa}$ (Young's modulus)

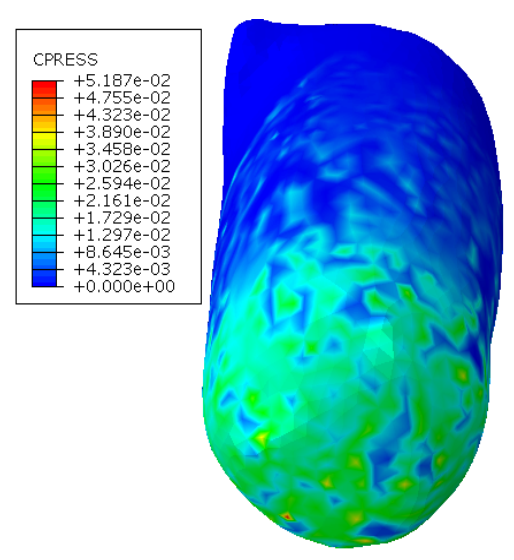

The Stump at implant 0.4 MPa (Young's modulus)

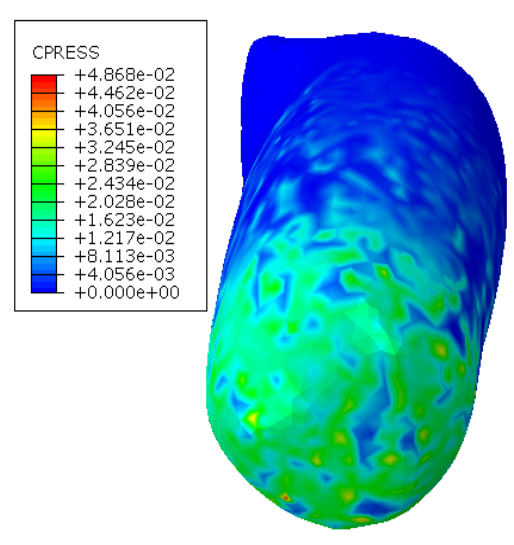

The Stump at implant 0.2 MPa (Young's modulus)
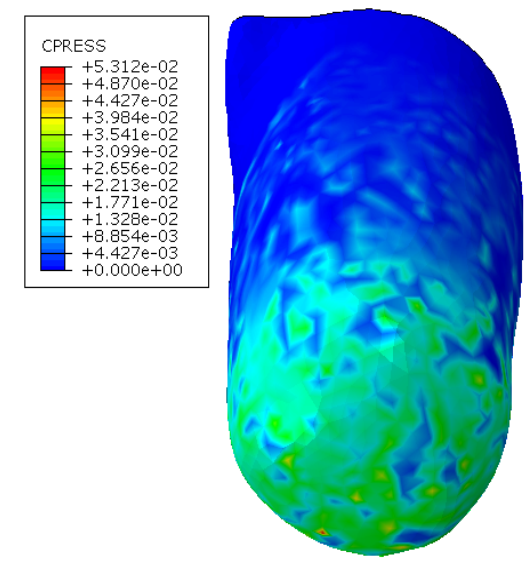

The Stump at implant 0.5 MPa (Young's modulus)

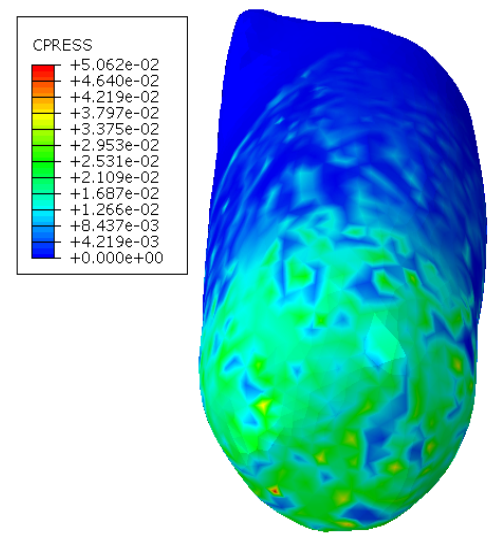

The Stump at implant 0.3 MPa

(Young's modulus)

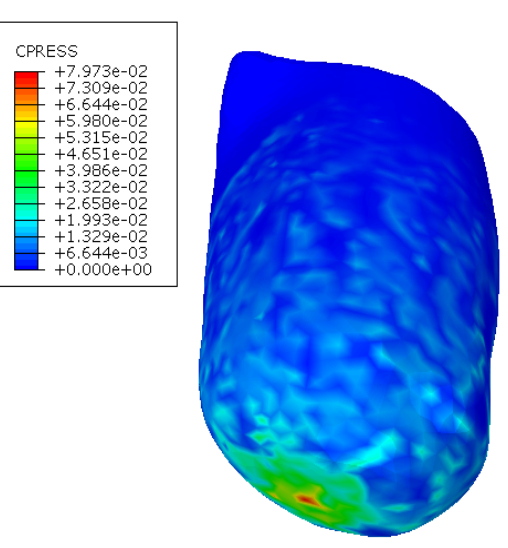

The Stump without implant

Figure 6: contact pressure distribution $(\mathrm{MPa})$ on the stump-prosthetic interface for all implant stiffness cases and the case without implant.

Fig 7 shows the distribution of longitudinal shear stress at the stump-prosthetic interface in all cases of implant stiffness and the case without an implant. It can be noticed that the case of limb without implant was recorded the highest values of shear stresses up to $18.4 \mathrm{kPa}$ the lowest shear stress was recorded in the limb in case of the least stiffness implant $(0.1$ $\mathrm{MPa}$ Young's modulus) up to $6.8 \mathrm{kPa}$. 

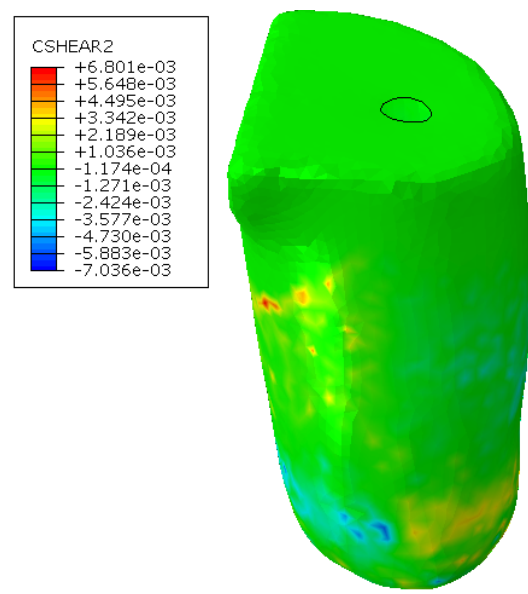

The Stump at implant $0.1 \mathrm{MPa}$ (Young's modulus)
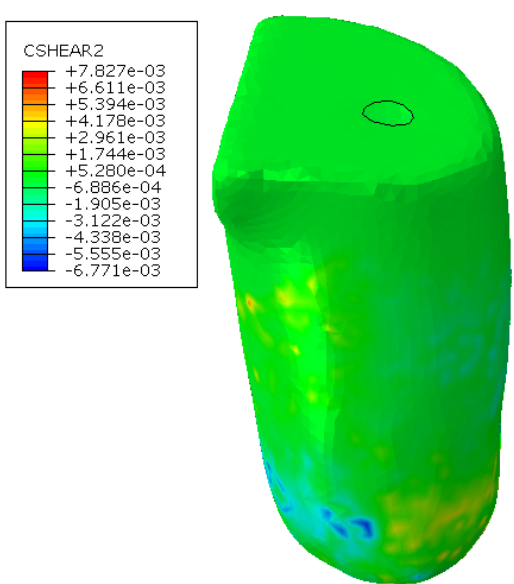

The Stump at implant 0.4 $\mathrm{MPa}$ (Young's modulus)
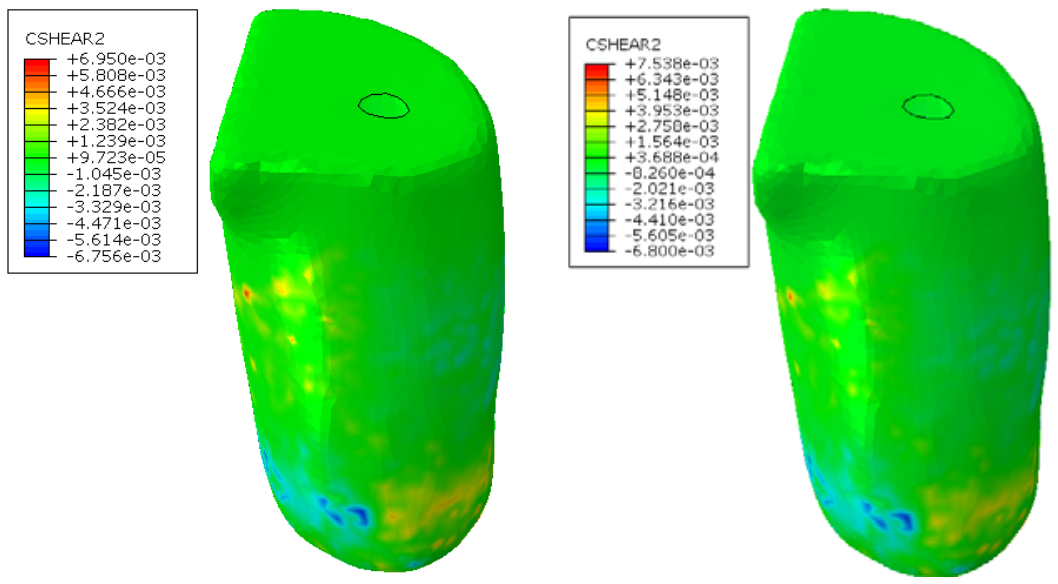

The Stump at implant $0.3 \mathrm{MPa}$

The Stump at implant $0.2 \mathrm{MPa}$ (Young's modulus)

(Young's modulus)
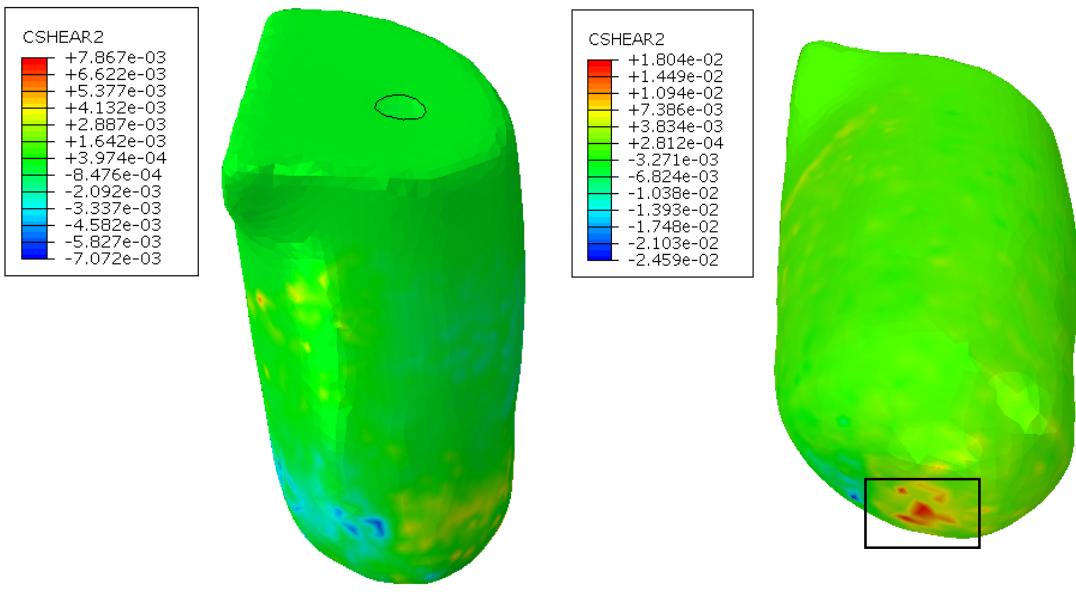

The Stump at implant $0.5 \mathrm{MPa}$ (Young's modulus)

Figure 7: Longitudinal shear stress distributio $(\mathrm{MPa})$ on the stump-prosthetic interface for all implant stiffness cases and the case without implant.

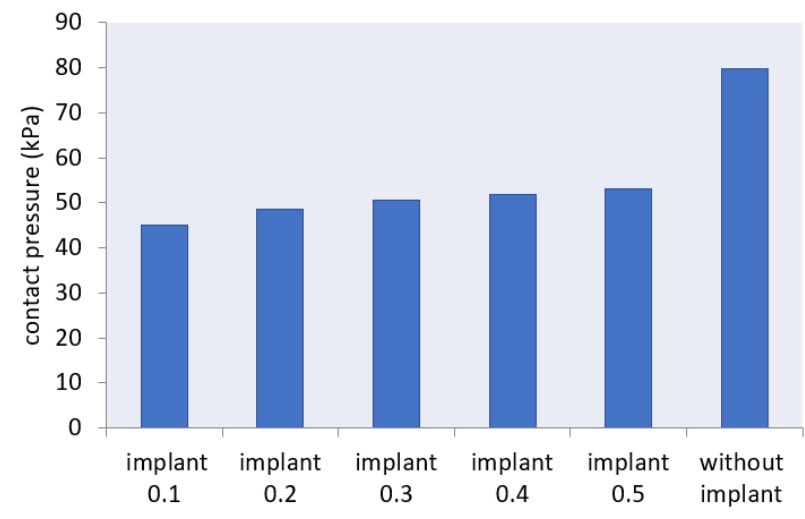

Figure 8: Peak contact pressure $(\mathrm{kPa})$ on the stump-prosthetic interface for all implant stiffness cases and the case without implant.

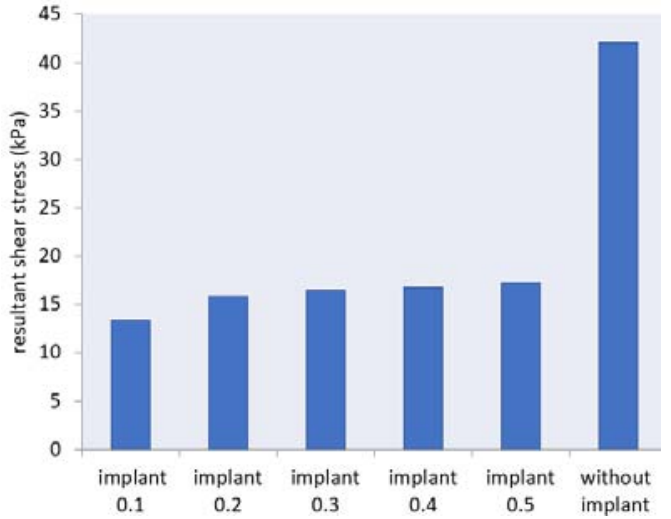

Figure 9: Resultant shear stress $(\mathrm{kPa})$ on the stump-prosthetic interface for all implant stiffness cases and the case without implant. 
Fig. 8 shows a histogram of the relationship between the peak contact pressure at the stump-prosthesis interface and the implant stiffness (elastic modulus, ranging from 0.1 to $0.5 \mathrm{MPa}$ ), The relationship between implant stiffness below the amputated bone and the contact pressure on the interface between the stump and the prosthesis was a direct relationship, as the higher the implant stiffness, the greater the stresses at the interface.

Fig. 9 shows a histogram of the relationship between the peak resultant shear stress at the stump-prosthesis interface and the implant stiffness. The resultant shear stress is the magnitude of the combination of longitudinal and circumferential components of shear stresses in the contact interface. The maximum resultant shear stress was recorded in the case of femur without implant up to $42.16 \mathrm{kPa}$. While the resultant shear stress increase from $13.3 \mathrm{KPa}$ in the case of implant 0.1 to $17.3 \mathrm{KPa}$ in the case of implant 0.5 .

\section{CONCLUSIONS}

B

y employing a non-linear finite element method (EFM) to investigate the stresses after trans-femoral amputation in the case of a soft implant below the amputated bone. We came out with conclusions, including that the implant under the amputated bone had a very clear effect in reducing stresses caused by body weight, whether inside the muscle tissue in the area below the amputated bone or on the interface between the limb and the prosthetic, as the difference between the peak contact pressure in the case without an implant $(79.7 \mathrm{KPa})$ and the case with implant 0.1(45 $\mathrm{KPa}$ ) was $34.7 \mathrm{KPa}$. We observed also that the relationship between implant stiffness below the amputated bone and the contact pressure on the interface between the stump and the prosthesis was a direct relationship, as the higher the implant stiffness, the greater the stresses at the interface.

This simulation predicted that the soft implant under an amputated bone is a very promising technique for relieving the patient's pain, problems of skin degradation, and even the inability to stand for a long time, as the contact pressures and the shear stress recorded were much less than those causing problems for the patient, according to Cagle study [6]. The results of this study reinforce the results of previous studies such Chillale's study [11] about the efficiency of this implant below the bone in reducing stresses at the stump-prosthetic interface. This implant may be a solution to the great problems suffered by amputee patients. These results remain hypothetical despite the efficiency of the finite element method further work is necessary to validate this result.

\section{REFERENCES}

[1] Ebskov, L. B. (1992). Level of lower limb amputation in relation to etiology: an epidemiological study. Prosthetics and Orthotics international, 16(3), pp. 163-167.DOI:10.3109/03093649209164335.

[2] Adler, A. I., Boyko, E. J., Ahroni, J. H., and Smith, D. G. (1999). Lower-extremity amputation in diabetes. The independent effects of peripheral vascular disease, sensory neuropathy, and foot ulcers. Diabetes care, 22(7), pp. 1029-1035. DOI: $10.2337 /$ diacare.22.7.1029.

[3] Ziegler-Graham, K., MacKenzie, E. J., Ephraim, P. L., Travison, T. G., and Brookmeyer, R. (2008), Estimating the prevalence of limb loss in the United States: 2005 to 2050, Archives of physical medicine and rehabilitation, 89(3), pp. 422-429.DOI: 10.1016/j.apmr.2007.11.005.

[4] Ali, S., Osman, N. A. A., Naqshbandi, M. M., Eshraghi, A., Kamyab, M., and Gholizadeh, H. (2012). Qualitative study of prosthetic suspension systems on transtibial amputees' satisfaction and perceived problems with their prosthetic devices. Archives of physical medicine and rehabilitation, 93(11), pp. 1919-1923. DOI: 10.1016/j.apmr.2012.04.024.

[5] Meulenbelt, H. E., Dijkstra, P. U., Jonkman, M. F., and Geertzen, J. H. (2006). Skin problems in lower limb amputees: a systematic review. Disability and rehabilitation, 28(10), pp. 603-608. DOI: 10.1080/09638280500277032.

[6] Cagle, J. C., Reinhall, P. G., Allyn, K. J., McLean, J., Hinrichs, P., Hafner, B. J., and Sanders, J. E. (2018). A finite element model to assess transtibial prosthetic sockets with elastomeric liners. Medical and biological engineering and computing, 56(7), pp.1227-1240. DOI: 10.1007/s11517-017-1758-z.

[7] Meng, Z., Wong, D. W. C., Zhang, M., and Leung, A. K. L. (2020). Analysis of compression/release stabilized transfemoral prosthetic socket by finite element modelling method. Medical Engineering and Physics, 83, pp. 123129. DOI: 10.1016/j.medengphy.2020.05.007.

[8] Ballit, A., Mougharbel, I., Ghaziri, H., and Dao, T. T. (2020). Fast soft tissue deformation and stump-socket interaction toward a computer-aided design system for lower limb prostheses. Irbm, 41(5), pp. 276-285.

DOI 10.1016/j.irbm.2020.02.003. 
[9] Boudjemaa, I., Sahli, A., Benkhettou, A., and Benbarek, S. (2021). Effect of multi-layer prosthetic foam liner on the stresses at the stump-prosthetic interface. Frattura ed Integrità Strutturale, 15(56), pp. 187-194.

DOI: $10.3221 /$ IGF-ESIS.56.15.

[10] Mbithi, F. M., Chipperfield, A. J., Steer, J. W., and Dickinson, A. S. (2019, July). Predictive Control for an Active Prosthetic Socket informed by FEA-based Tissue Damage Risk Estimation. In 2019 41st Annual International Conference of the IEEE Engineering in Medicine and Biology Society (EMBC) (pp. 2073-2076). IEEE. DOI: $10.1109 /$ EMBC.2019.8857155.

[11] Chillale, T. P., Kim, N. H., and Smith, L. N. (2019). Mechanical and finite element analysis of an innovative orthopedic implant designed to increase the weight carrying ability of the femur and reduce frictional forces on an amputee's stump. Military medicine, 184(Supplement_1), pp. 627-636. DOI: 10.1093/milmed/usy382.

[12] VélezZea, J. A., Bustamante Góez, L. M., and Villarraga Ossa, J. A. (2015). Relation between residual limb length and stress distribution over stump for transfemoral amputees. Revista EIA, (23), pp. 107-115.

[13] Zhang, L., Zhu, M., Shen, L., and Zheng, F. (2013, July). Finite element analysis of the contact interface between trans-femoral stump and prosthetic socket. In 2013 35th annual international conference of the IEEE engineering in medicine and biology society (Embc), pp. 1270-1273. DOI: 10.1109/EMBC.2013.6609739.

[14] Lacroix, D., and Patiño, J. F. R. (2011), Finite element analysis of donning procedure of a prosthetic transfemoral socket, Annals of biomedical engineering, 39(12), 2972. DOI: 10.1007/s10439-011-0389-z.

[15] Ramírez, J. F., and Vélez, J. A. (2012). Incidence of the boundary condition between bone and soft tissue in a finite element model of a transfemoral amputee. Prosthetics and orthotics international, 36(4), pp. 405-414. DOI:10.1177/0309364612436409.

[16] Lee, W., Zhang, C.C., Ming, J.I.A., Xiaohong, et al. (2004). Finite element modeling of the contact interface between trans-tibial residual limb and prosthetic socket. Medical engineering \& physics, 26(8), pp. 655-662. DOI: 10.1016/j.medengphy.2004.04.010.

[17] Lin, C. C., Chang, C. H., Wu, C. L., Chung, K. C., and Liao, I. C. (2004). Effects of liner stiffness for trans-tibial prosthesis: a finite element contact model. Medical engineering \& physics, 26(1), pp. 1-9. DOI: 10.1016/S1350-4533(03)00127-9.

[18] Jia, X., Zhang, M., and Lee, W. C. (2004). Load transfer mechanics between trans-tibial prosthetic socket and residual limb_dynamic effects. Journal of biomechanics, 37(9), pp. 1371-1377. DOI: 10.1016/j.jbiomech.2003.12.024.

[19] Mak, A. F., Zhang, M., and Boone, D. A. (2001). State-of-the-art research in lower-limb prosthetic biomechanicssocket interface: a review. Journal of rehabilitation research and development, 38(2), pp. 161-174.

[20] Dickinson, A. S., Steer, J. W., and Worsley, P. R. (2017). Finite element analysis of the amputated lower limb: a systematic review and recommendations. Medical engineering \& physics, 43, pp. 1-18. DOI: $10.1016 /$ j.medengphy.2017.02.008.

[21] Vantadori, S., Carpinteri, A., Fortese, G., Ronchei, C., Scorza, D., and Berto, F. (2016). Two-parameter fracture model for cortical bone. FratturaedIntegritàStrutturale, 10(37), pp. 215-220. DOI: 10.3221/IGF-ESIS.37.28.

[22] Aliha, M. R. M., Ghazi, H., and Ataei, F. (2019). Experimental fracture resistance study for cracked bovine femur bone samples. FratturaedIntegritàStrutturale, 13(50), pp. 602-612. DOI: 10.3221/IGF-ESIS.50.51.

[23] Surapureddy, R., Schönning, A., Stagon, S., and Kassab, A. (2016). Predicting pressure distribution between transfemoral prosthetic socket and residual limb using finite element analysis. International Journal of Experimental and Computational Biomechanics, 4(1), pp. 32-48.

[24] Ramos, A., and Simoes, J. A. (2006), Tetrahedral versus hexahedral finite elements in numerical modelling of the proximal femur, Medical engineering \& physics, 28(9), pp. 916-924. DOI: 10.1016/j.medengphy.2005.12.006. 